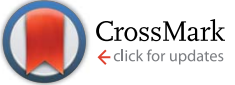

Cite this: RSC Adv., 2016, 6, 44279
Received 14th February 2016 Accepted 27th April 2016

DOI: $10.1039 / \mathrm{c} 6 \mathrm{ra04066g}$

www.rsc.org/advances

\section{Design of porphyrin-based conjugated microporous polymers with enhanced singlet oxygen productivity $\dagger$}

\begin{abstract}
Jan Hynek, ${ }^{\text {ab }}$ Jiři Rathouský, ${ }^{c}$ Jan Demel ${ }^{a}$ and Kamil Lang*a
Novel non-toxic materials with antimicrobial surfaces are needed for medicinal applications. Potential alternatives for bacterial inactivation include materials that produce singlet oxygen, $\mathrm{O}_{2}\left({ }^{1} \Delta_{\mathrm{g}}\right)$, a short-lived, highly oxidative, and cytotoxic species. We synthesized a promising group of materials, porphyrin-based conjugated microporous polymers (CMPs), which effectively generate $\mathrm{O}_{2}\left({ }^{1} \Delta_{g}\right)$ under visible light irradiation. CMPs were rationally designed and synthesized to maximize $\mathrm{O}_{2}\left({ }^{1} \Delta_{g}\right)$ production. A strategy based on three-dimensional frameworks allowed the immediate environment of the porphyrin units to be tuned and their structure-property relationships to be elucidated. We investigated the photophysical and photochemical properties of the frameworks and compared them with the properties of porphyrinbased CMPs and metal-organic frameworks. In general, the $\mathrm{O}_{2}\left({ }^{1} \Delta_{\mathrm{g}}\right)$ production activity of the CMPs correlated with neither the surface area nor with the pore volume. The novel CMPs displayed high $\mathrm{O}_{2}\left({ }^{1} \Delta_{\mathrm{g}}\right)$ production, were stable in organic solvents, and did not undergo measurable photobleaching.
\end{abstract}

\section{Introduction}

In recent decades, great effort has been devoted to the development of antimicrobial materials that prevent the formation of bacterial colonies or directly kill bacteria upon contact. A wide range of strategies has been employed including the use of silver ions, antibiotics, or nanostructured metal oxides, such as $\mathrm{TiO}_{2}$ and $\mathrm{ZnO}$, combined with UV irradiation. ${ }^{1}$ Growing resistance against antibiotics and other chemotherapeutics has led to a search for antimicrobial treatments to which pathogenic microorganisms will not be easily able to develop resistance. A very promising alternative is photodynamic inactivation based on the formation of reactive oxygen species (ROS), including singlet oxygen, $\mathrm{O}_{2}\left({ }^{1} \Delta_{\mathrm{g}}\right)$, a short-lived, highly oxidative, and cytotoxic species, generated in situ via energy transfer from an excited molecule of a photosensitizer to an oxygen molecule. ${ }^{\mathbf{1 - 4}}$ The development of nanomaterials producing $\mathrm{O}_{2}\left({ }^{1} \Delta_{\mathrm{g}}\right)$ has blossomed as a field of great interest because of the ease with which their functionality is both rapidly switched on and off by light and without introducing

\footnotetext{
${ }^{a}$ Institute of Inorganic Chemistry of the Czech Academy of Sciences, v.v.i, Husinec-Řez 1001, 25068 Řež, Czech Republic.E-mail: lang@iic.cas.cz

${ }^{b}$ Department of Inorganic Chemistry, Faculty of Science, Charles University in Prague, Hlavova 2030, 12843 Praha 2, Czech Republic

'J. Heyrovsky Institute of Physical Chemistry of the Czech Academy of Sciences, v.v.i., Dolejškova 3, 18223 Praha 8, Czech Republic

$\dagger$ Electronic supplementary information (ESI) available: Synthetic procedures, ${ }^{13} \mathrm{C}$ MAS-NMR spectra, FTIR, thermal analyses, adsorption isotherms, adsorption and luminescence spectra, and the photosensitized activity of 3D-PdTPP dispersions. See DOI: 10.1039/c6ra04066g
}

other reactants into the system. Novel non-toxic materials displaying antimicrobial properties under visible light irradiation are needed for medicinal applications. In this respect, porphyrin-based polymers that effectively generate $\mathrm{O}_{2}\left({ }^{1} \Delta_{\mathrm{g}}\right)$ represent a promising group of materials.

Porous polymers are a fast growing class of materials because of their high surface areas, tunable structures, good diffusion properties, and variable chemical functionality. ${ }^{5,6}$ Among others, purely organic structures such as covalent organic frameworks (COFs) ${ }^{7}$ and conjugated microporous polymers $(\mathrm{CMPs})^{8}$ are receiving increased attention. In COFs, the building blocks are connected by reversibly formed bonds such as boroxine, ${ }^{9}$ boronyl ester, ${ }^{10}$ triazine, ${ }^{11}$ or imine, ${ }^{12}$ and therefore, the resulting materials are crystalline. On the other hand, their chemical stability can be lower than that of CMPs produced by ethynyl cyclotrimerization, ${ }^{\mathbf{1 3}}$ metathesis, ${ }^{\mathbf{1 4}}$ Suzuki, ${ }^{15}$ or Sonogashira ${ }^{8}$ polycondensations.

CMPs have a three dimensional structure created by condensation polymerization with one of the two monomers bearing more than two reactive end groups. Commonly, building blocks of porous polymers are rigid molecules with a well-defined geometry allowing a rational design of networks with the desired size and topology of pores. Thus, the use of molecules containing strictly $\mathrm{sp}^{2}$ hybridized carbon atoms, such as $1,3,5$-trisubstituted benzenes ${ }^{16}$ or $5,10,15,20$-tetrasubstituted porphyrins, ${ }^{17}$ leads to planar networks stacked by $\pi-\pi$ interactions (abbreviated as 2D CMPs), whereas molecules with $\mathrm{sp}^{3}$ carbon or silicon atoms (e.g., tetraphenyl methane, ${ }^{\mathbf{1 8 , 1 9}}$ tetraphenyl silane,$^{\mathbf{2 0}}$ or adamantane ${ }^{\mathbf{2 1 , 2 2}}$ ) enable the preparation of 
materials with a three-dimensional covalently bound network (abbreviated as 3D CMPs).

Porphyrin molecules are commonly used building blocks for the construction of porous polymers because of their rigidity, planar geometry, and chemical stability. In addition, porphyrin units add synergistic functionalities resulting in materials suitable for gas storage and separation, ${ }^{23}$ sorption, ${ }^{24}$ optoelectronic devices, ${ }^{25}$ and electrocatalytic ${ }^{26}$ and catalytic applications. ${ }^{27,28}$ Porphyrins are also among the dyes that can be excited by visible light to excited singlet and triplet states in high quantum yields. The triplet states interact with molecular oxygen via energy transfer resulting in the formation of $\mathrm{O}_{2}\left({ }^{1} \Delta_{\mathrm{g}}\right)$. In recent years, a number of composite materials containing porphyrins for antimicrobial applications have been developed. $^{29-31}$ The photosensitizing properties of porphyrin molecules are strongly dependent on surrounding environment ${ }^{32}$ because commonly occurring $\pi-\pi$ porphyrin stacking diminishes the photosensitizing properties. Therefore, tailoring properties for a specific purpose requires a high degree of control over the porphyrin environment. This is difficult to achieve in amorphous materials such as silica-based composites or nanowires. For these reasons, crystalline materials with an organized arrangement of porphyrin units have been extensively investigated, such as layered metal hydroxides ${ }^{33-35}$ and metal-organic frameworks (MOFs); ${ }^{36-38}$ however, these materials often possess limited chemical stability in aqueous environments. CMPs represent a unique combination of the stability of the polymeric structures bonded by $\mathrm{C}-\mathrm{C}$ bonds with added structural variability and control.

In this work, we synthesized novel CMPs constructed from porphyrin building blocks suitable for the design of antimicrobial materials. To elucidate their structure-property relationship, we investigated their photophysical and photochemical properties and compared these properties with the properties of two known CMPs with the planar configuration of the building blocks and porphyrin-based MOFs. The newly prepared CMPs displayed markedly higher $\mathrm{O}_{2}\left({ }^{1} \Delta_{\mathrm{g}}\right)$ production than 2D CMPs and MOFs, were stable in organic solvents, and did not undergo measurable photobleaching.

\section{Experimental}

\section{Materials}

Tetraphenyl methane (Manchester Organics), $\mathrm{Br}_{2}$, BuLi $(2.5 \mathrm{M}$ in hexanes), $\mathrm{B}(\mathrm{O}-\mathrm{iPr})_{3}, \mathrm{Pd}\left(\mathrm{PPh}_{3}\right)_{4}$, palladium acetylacetonate $\left(\mathrm{Pd}(\mathrm{acac})_{2}\right)$, pyrrole, benzaldehyde, pinacol, trifluoroacetic acid, 2,3-dichloro-5,6-dicyano-1,4-benzoquinone (DDQ), benzene-1,4diboronic acid (11), $\mathrm{Et}_{3} \mathrm{~N}, \mathrm{MgSO}_{4}$ (all Sigma-Aldrich), 5,10,15,20tetrakis(4-bromophenyl)porphyrin $\quad(\mathbf{8}, \quad$ Frontier Scientific Europe, Ltd., UK), 5,15-dibromo-10,20-diphenylporphyrin (10, PorphyChem, France), $\mathrm{NaOH}, \mathrm{HCl}$, acetone, diethyl ether, hexane (mixture of isomers), $\mathrm{CH}_{2} \mathrm{Cl}_{2}$ (all Lachner, Czech Republic), $\mathrm{NaCl}, \quad \mathrm{NaHCO}_{3}, \quad \mathrm{~K}_{2} \mathrm{CO}_{3}$ (all Lachema, Czech Republic), tetrahydrofuran (THF), methanol (MeOH), and 1,4dioxane (all Penta, Czech Republic) were used as purchased. For the Suzuki coupling reaction, 1,4-dioxane was dried with $\mathrm{Na} / \mathrm{Ph}_{2} \mathrm{CO}$ and distilled under $\mathrm{N}_{2}$. HPLC grade acetonitrile
(ACN) (Chromasolv Plus, Sigma-Aldrich) was used for all photophysical measurements.

\section{Instrumental methods}

The porosity and adsorption properties were probed by measuring nitrogen adsorption isotherms at the boiling point of liquid nitrogen $(c a .77 \mathrm{~K})$ with a Micromeritics ASAP 2010 apparatus. Prior to adsorption experiments, the samples were evacuated at $80^{\circ} \mathrm{C}$ for at least 24 hours. Because of the complex character of CMPs, the adsorption isotherms were analysed by several techniques including the BET method, Broekhoff-de Boer (BdB) $t$-plots, and DFT/NLDFT methods for various pore shapes and interactions potentials (as provided by the Micromeritics software), with the aim to achieve consistent texture parameters.

${ }^{1} \mathrm{H}$ and ${ }^{13} \mathrm{C}$ NMR spectroscopy were performed on a Varian Mercury 400 Plus Instrument $\left({ }^{1} \mathrm{H}, 399.98 \mathrm{MHz} ;{ }^{13} \mathrm{C}, 100.59\right.$ $\mathrm{MHz})$ at $298 \mathrm{~K}$. The chemical shifts $(\delta / \mathrm{ppm})$ are given relative to the residual ${ }^{1} \mathrm{H}$ signal of the deuterated solvent. Thermal analyses were carried out using a Setaram SETSYS Evolution-16MS instrument coupled with a mass spectroscopy system. The measurements were performed in a synthetic air atmosphere

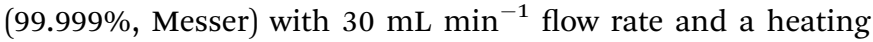
rate of $5{ }^{\circ} \mathrm{C} \mathrm{min}^{-1}$. Fourier transform infrared spectra (FTIR) were recorded with a Nicolet NEXUS 670-FT spectrometer in KBr pellets. The elemental analysis of CHN was performed using a standard combustion technique.

The UV/Vis absorption spectra of CMP dispersions in acetonitrile were recorded on a Perkin Elmer Lambda 35. Solid samples were recorded on the same instrument using a Labsphere RSA-PE-20 integration sphere accessory. The luminescence properties were monitored on a Fluorolog 3 spectrometer equipped with a cooled TBX-05-C photon detection module (Horiba Jobin Yvon) or with a Hamamatsu H10330-45 photomultiplier for measurement of the $\mathrm{O}_{2}\left({ }^{1} \Delta_{\mathrm{g}}\right)$ emission spectra. The fluorescence lifetime measurements were performed using a laser-diode excitation at $405 \mathrm{~nm}$ (NanoLED405LH, pulse width $750 \mathrm{ps}$, repetition rate $1 \mathrm{MHz}$ ). The emission was recorded at fluorescence maxima at 660 and $720 \mathrm{~nm}$ using a cooled TBX-05-C photon detection module in a timecorrelated single-photon counting regime. The decay curves were fitted with exponential functions using the iterative reconvolution procedure of the DAS6 software (v. 6.4, Horiba Jobin Yvon, 2009).

\section{Photosensitization activity of CMPs}

The photosensitizing ability of CMPs was assessed using the reaction of photoproduced $\mathrm{O}_{2}\left({ }^{1} \Delta_{\mathrm{g}}\right)$ with 9,10-diphenylanthracene leading to the corresponding endoperoxide. The course of the reaction was followed by UV/Vis spectroscopy as it is indicated by a decreasing absorption of 9,10-diphenylanthracene between 230 and $410 \mathrm{~nm}$. In each experiment, $1.0 \mathrm{mg}$ of CMP was dispersed in $20 \mathrm{~mL}$ of $10^{-4} \mathrm{M}$ 9,10-diphenylanthracene in acetonitrile and placed in a quartz cuvette. After sonication for $10 \mathrm{~s}$, the dispersion was stirred with a magnetic bar and continuously irradiated by a $300 \mathrm{~W}$ Xe lamp (ozone free, 
Table 1 Reaction conditions used for the syntheses of CMPs

\begin{tabular}{|c|c|c|c|c|c|c|}
\hline CMP & Porphyrin/mg (mmol) & Linker/mg (mmol) & $\mathrm{Pd}\left(\mathrm{PPh}_{3}\right)_{4} / \mu \mathrm{mol}$ & $\mathrm{K}_{2} \mathrm{CO}_{3} / \mathrm{mL}$ & 1,4-Dioxane $/ \mathrm{mL}$ & Yield/mg \\
\hline 3D-TPP & $5,87(0.10)$ & $1,32(0.05)$ & 10 & 2 & 8 & $46(60 \%)$ \\
\hline 3D-PdTPP & $7,88(0.10)$ & $2,25(0.05)$ & 10 & 2 & 12 & $62(71 \%)$ \\
\hline 2D-TPP & $8,93(0.10)$ & 11, $33(0.20)$ & 10 & 4 & 16 & $64(84 \%)$ \\
\hline 2D-PdTPP & $9,310(0.30)$ & $11,99(0.60)$ & 30 & 12 & 36 & $122(47 \%)$ \\
\hline
\end{tabular}

Newport) equipped with a water filter and a glass filter (cut-on at $435 \mathrm{~nm}$, Newport) for 3 hours. The aliquots were taken at regular time intervals, centrifuged $(20000 \mathrm{rpm}, 20 \mathrm{~min}$, Hermle Z 36 HK centrifuge), filtered through a $0.2 \mu \mathrm{m}$ Millipore filter, and inserted into a $10 \times 10 \mathrm{~mm}$ quartz cell to measure the corresponding UV/Vis spectrum. The same procedure was used for the studied MOFs. The irradiation experiments were performed in air; in specific cases, the dispersion was purged with argon for 30 min prior to irradiation.

\section{Synthetic procedures}

Linkers 1 and 2, porphyrin precursors 3 and 4, and porphyrin 6 were synthesized according to the procedures reported in literature (for the synthetic procedures see the ESI, Scheme $\mathrm{S} 1 \dagger) .^{39-42}$

Preparation of 5,15-bis[4-(4,4,5,5-tetramethyl-1,3,2dioxaborolan-2-yl)phenyl]-10,20-diphenylporphyrin

Compounds 3 (1.11 g; $5 \mathrm{mmol})$ and 4 (1.16 g; $5 \mathrm{mmol})$ were dissolved in argon-degassed $\mathrm{CH}_{2} \mathrm{Cl}_{2}(500 \mathrm{~mL})$ in a $1000 \mathrm{~mL}$ twonecked round-bottom flask. The mixture was evacuated and purged with argon three times and the reaction was initiated by the addition of trifluoroacetic acid $(0.23 \mu \mathrm{L} ; 1.7 \mathrm{mmol})$. The reaction flask was fully covered with aluminium foil to minimize photoreactions induced by sunlight. After stirring for $24 \mathrm{~h}$ at room temperature, DDQ ( $1.36 \mathrm{~g} ; 6 \mathrm{mmol})$ was added and the reaction mixture was further stirred for $1 \mathrm{~h}$. The reaction was quenched by the addition of $\mathrm{Et}_{3} \mathrm{~N}(0.42 \mathrm{~mL} ; 1.7 \mathrm{mmol})$. The resulting mixture was washed with $\mathrm{NaCl}$ solution and the organic fraction was dried over $\mathrm{MgSO}_{4}$. The product was purified by flash chromatography on a silica gel column using $\mathrm{CH}_{2} \mathrm{Cl}_{2}$ as an eluent. Yield: $357 \mathrm{mg}, 16 \%$.

${ }^{1} \mathrm{H} \mathrm{NMR}\left(\mathrm{CDCl}_{3}\right): \delta-2.76(\mathrm{~s}, 2 \mathrm{H}) ; 1.52(\mathrm{~s}, 24 \mathrm{H}) ; 7.74-7.82(\mathrm{~m}$, $8 \mathrm{H}) ; 8.20-8.28(\mathrm{~m}, 10 \mathrm{H}) ; 8.86(\mathrm{~s}, 8 \mathrm{H}) .{ }^{13} \mathrm{C} \mathrm{NMR}\left(\mathrm{CDCl}_{3}\right): \delta 25.42$; $84.49 ; 120.42 ; 120.54 ; 127.04 ; 128.07 ; 131.48 ; 133.38 ; 134.51$; $134.89 ; 142.52 ; 145.44$.

\section{General procedure for preparation of $\operatorname{Pd}(\mathrm{II})$ porphyrins ${ }^{43}$}

Porphyrin and $\operatorname{Pd}(\mathrm{acac})_{2}$ were dissolved in toluene, and the mixture was refluxed at $110{ }^{\circ} \mathrm{C}$ for $24 \mathrm{~h}$. The reaction mixture was filtered, and the solvent was evaporated. The product was triturated with hexane to remove excess $\operatorname{Pd}(\mathrm{acac})_{2}$ and the residual solvent. The product purity was checked by NMR and luminescence emission spectroscopy. If the sample still contained non-metallated porphyrin, then the procedure was repeated.
Preparation of $\operatorname{Pd(II)-5,15-bis(4-bromophenyl)-10,20-~}$ diphenylporphyrin (7). Porphyrin 6 (232 mg; $0.3 \mathrm{mmol})$, $\operatorname{Pd}(\mathrm{acac})_{2}(110 \mathrm{mg} ; 0.36 \mathrm{mmol})$ and toluene $(200 \mathrm{~mL})$ were used.

${ }^{1} \mathrm{H} \mathrm{NMR}\left(\mathrm{CDCl}_{3}\right): \delta 7.75\left(\mathrm{~d}, 6 \mathrm{H},{ }^{3} J_{\mathrm{HH}}=7.6 \mathrm{~Hz}\right) ; 7.87(\mathrm{~d}, 4 \mathrm{H}$, $\left.{ }^{3} J_{\mathrm{HH}}=6.8 \mathrm{~Hz}\right) ; 8.03\left(\mathrm{~d}, 4 \mathrm{H},{ }^{3} J_{\mathrm{HH}}=8.4 \mathrm{~Hz}\right) ; 8.16\left(\mathrm{~d}, 4 \mathrm{H},{ }^{3} J_{\mathrm{HH}}=\right.$ $6.4 \mathrm{~Hz}) ; 8.81(\mathrm{dt}, 8 \mathrm{H})$.

Preparation of $\mathrm{Pd}(\mathrm{II})-5,10,15,20$-tetrakis(4-bromophenyl) porphyrin (9). Porphyrin 8 (279 mg; $0.3 \mathrm{mmol}), \mathrm{Pd}(\mathrm{acac})_{2}(110$ $\mathrm{mg} ; 0.36 \mathrm{mmol})$ and toluene $(300 \mathrm{~mL})$ were used.

${ }^{1} \mathrm{H} \mathrm{NMR}\left(\mathrm{CDCl}_{3}\right): \delta 7.88\left(\mathrm{~d}, 8 \mathrm{H},{ }^{3} J_{\mathrm{HH}}=8.0 \mathrm{~Hz}\right) ; 8.02(\mathrm{~d}, 8 \mathrm{H}$, $\left.{ }^{3} J_{\mathrm{HH}}=8.0 \mathrm{~Hz}\right) ; 8.80(\mathrm{~s}, 8 \mathrm{H})$.

\section{General procedure for CMP polymerization}

A Schlenk tube charged with the corresponding porphyrin, linker, and $\mathrm{K}_{2} \mathrm{CO}_{3}(0.4 \mathrm{M}$ solution) was purged three times with argon. Then, a solution of $\mathrm{Pd}\left(\mathrm{PPh}_{3}\right)_{4}$ catalyst in dry 1,4-dioxane was added, and the reaction mixture was degassed in three freeze-pump-thaw cycles. The amounts of reactants, catalyst, and dioxane are given in Table 1 . The reaction mixture was stirred at $100{ }^{\circ} \mathrm{C}$ for $24 \mathrm{~h}$. The resulting precipitate was collected by filtration and thoroughly washed with water, $\mathrm{MeOH}$, acetone, and THF. The solid product was purified in a Soxhlet extractor with THF, $\mathrm{MeOH}$, and acetone for at least $24 \mathrm{~h}$ with each solvent.

\section{Results and discussion}

\section{Syntheses and textural properties}

Scheme 1 depicts the synthetic strategy for a series of CMPs. Polymerization of substituted porphyrins with linkers was performed using Suzuki-Miyaura cross-coupling reactions forming robust porous polymeric structures connected via $\mathrm{C}-\mathrm{C}$ bonds. The material robustness allowed their purification by Soxhlet extraction, which ensured the complete removal of unreacted porphyrins. The prepared CMPs were insoluble solids that can be well dispersed in organic solvents such as acetonitrile or dimethylformamide; the hydrophobicity of the CMPs prevented to use water for solution processing.

Polymers 3D-TPP, 3D-PdTPP, and 3D-DPP were designed by a combination of well-defined rigid 4-connected tetrahedral and 2-connected linear shaped building units to form a diamondlike structure with accessible porphyrin centres in pores (Fig. 1). The size of the cavities was modulated using differently sized building units while maintaining the porous structure. As anticipated, the reaction between two equivalents of trans-disubstituted porphyrin building blocks and one 

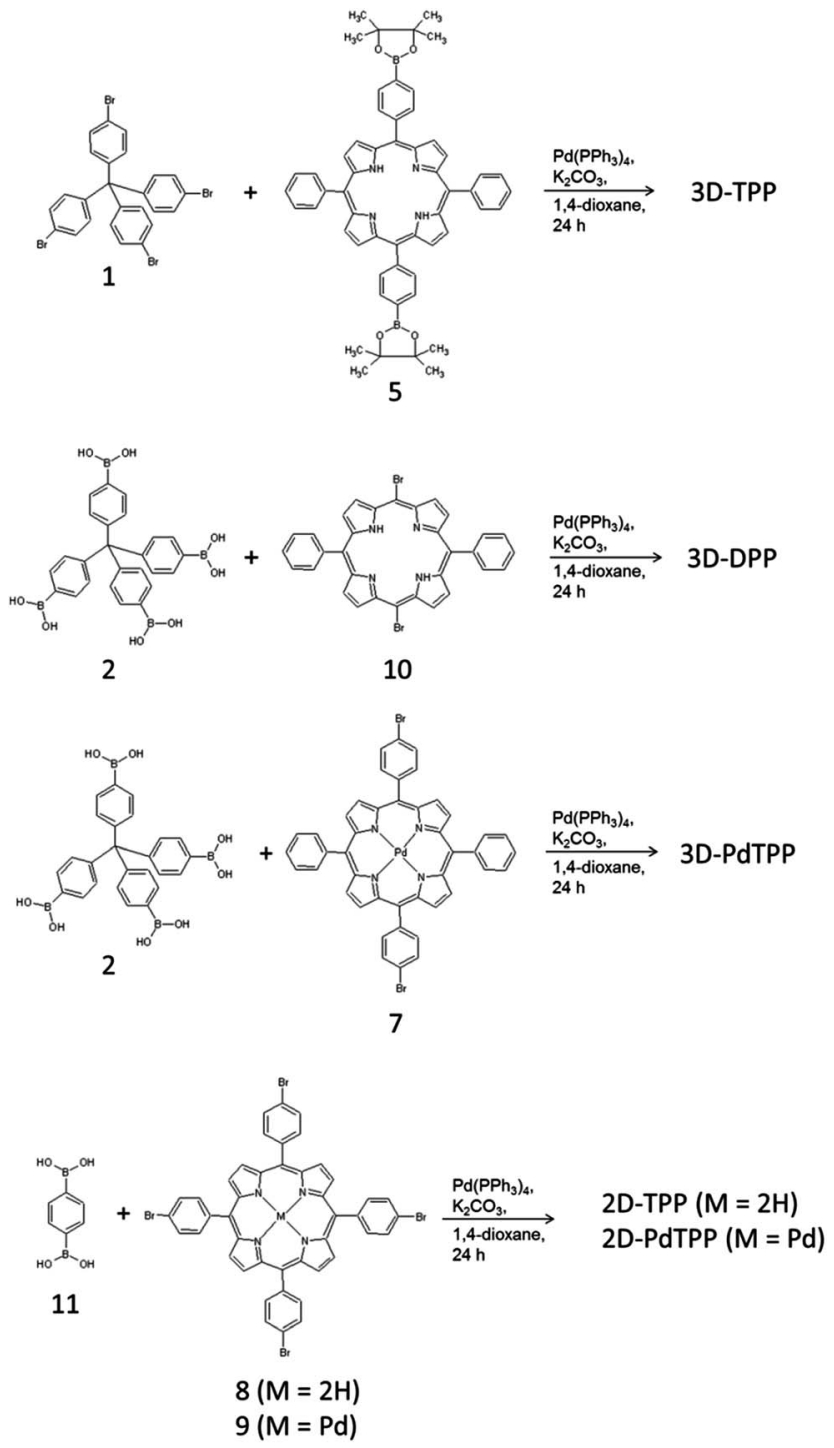

Scheme 1 Syntheses of CMPs including the abbreviations used in the text.

equivalent of tetraphenyl methane linkers in 1,4-dioxane catalysed by $\mathrm{Pd}\left(\mathrm{PPh}_{3}\right)_{4}$ resulted in formation of 3D CMPs in high yields. The syntheses and properties of these materials are reported for the first time. 3D-DPP was constructed using
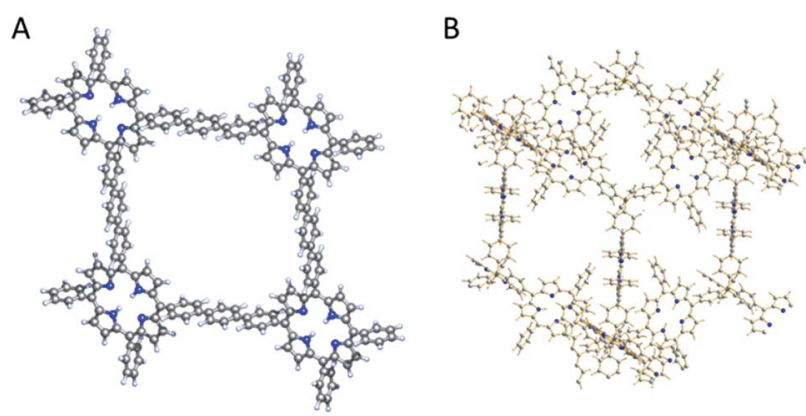

Fig. 1 Idealized structure of 2D-TPP (A) and 3D-DPP (B) networks. 5,15-dibromo-10,20-diphenylporphyrin (10) to obtain a structure with narrow pores due to a close arrangement of the porphyrin units that are separated only by tertiary substituted carbon atoms breaking their conjugation in the polymer backbone. To enlarge the distance between the porphyrin units, tetraphenyl porphyrins 5 or 7 were the building blocks for 3D-TPP and 3D-PdTPP, respectively. Pd(II) in 3D-PdTPP brings an additional photofunctionality to the material.

For comparison purposes, two 2D CMPs were synthesized using a method derived from recently published procedures. ${ }^{27}$ 2D-TPP was built using tetrasubstituted tetraphenyl porphyrin 8 connected by 1,4-phenylene linkers 11, and the analogous 2D-PdTPP was prepared using Pd(II) porphyrin 9 instead of 8. Based on the idealized structures of the 2D CMP units, the porphyrin layers are closely stacked, forming pores oriented perpendicularly to the porphyrin plane and thus limiting the accessibility of the porphyrin centres (Fig. 1).

To optimize the $\mathrm{O}_{2}\left({ }^{1} \Delta_{\mathrm{g}}\right)$ productivity investigated in the following experiments, $\operatorname{Pd}(\mathrm{II})$ porphyrins were used for the preparation of 2D-PdTPP and 3D-PdTPP (Scheme 1). Apart from the altered photophysical properties, tetracoordinated $\mathrm{Pd}(\mathrm{II})$ cation imposes a planar conformation on the porphyrin unit, thus increasing the rigidity of the CMPs structure.

The CMPs were characterized by various analytical techniques including ${ }^{13} \mathrm{C}$ MAS-NMR, FTIR, thermogravimetric analysis, and elemental analysis, and their textural properties were assessed by the analysis of $\mathrm{N}_{2}$ adsorption isotherms. The ${ }^{13} \mathrm{C}$ MAS-NMR spectra (Fig. S1 $\dagger$ ) indicated the signals of tertiary and quaternary pyrrole carbon atoms in the range of 118-121 and 152-155 ppm, respectively. The intensive peaks at $141 \mathrm{ppm}$ were attributed to both quaternary phenylene and meso-carbon atoms of the porphyrin rings. The most intensive peak at 127 ppm can be ascribed to tertiary phenylene carbon atoms. In addition, 3D CMP materials showed peaks of quaternary carbon and tertiary phenylene carbon atoms of tetraphenyl methane at 65 and $131 \mathrm{ppm}$, respectively. These results suggest that the spectra of CMPs are in agreement with their expected network structure as presented in Fig. 1. The FTIR spectra of CMPs exhibited vibrational peaks characteristic for porphyrins: stretching aromatic $\mathrm{C}-\mathrm{H}$ vibrations in the range of 3022-3054 $\mathrm{cm}^{-1}$, a sharp peak at $794-798 \mathrm{~cm}^{-1}$ corresponding to pyrrole ring vibration, and an $\mathrm{N}-\mathrm{H}$ stretching vibration at $3313 \mathrm{~cm}^{-1}$ that disappeared in palladium analogues 2D-PdTPP and $3 \mathrm{D}$ PdTPP (Fig. S2†).

Thermogravimetric analyses of 3D CMPs made of metal-free porphyrins revealed thermal stability up to $300{ }^{\circ} \mathrm{C}$ (Fig. S3 and $\mathrm{S} 4 \dagger)$. The most thermally stable was 2D-TPP decomposing from approximately $350{ }^{\circ} \mathrm{C}$ (Fig. S5 $\dagger$ ). On the other hand, Pdporphyrin based CMPs decomposed from approximately $250{ }^{\circ} \mathrm{C}$, which could be due to palladium-catalysed oxidation (Fig. S6 and S7†). A partial mass loss below decomposition temperature was due to the evaporation of residual solvents. The decomposition of the samples was indicated by the coincident evolution of the gaseous products $\mathrm{CO}_{2}, \mathrm{H}_{2} \mathrm{O}$, and $\mathrm{NO}_{2}$. Elemental analyses of CMPs showed that the weight percentages of $\mathrm{C}, \mathrm{H}$, and $\mathrm{N}$ were slightly lower than the 
theoretical values of their ideal infinite polymers, which can be caused by the presence of terminal groups (Table $\mathrm{S} 1 \dagger$ ).

A parameter that influences the ability of materials to produce $\mathrm{O}_{2}\left({ }^{1} \Delta_{\mathrm{g}}\right)$ is the accessibility of the excited porphyrin units to molecular oxygen. Therefore, the permanent porosity of CMPs was investigated by nitrogen sorption measurements at $77 \mathrm{~K}$. These measurements revealed considerable adsorption at low pressures $\left(P / P_{0}<0.1\right)$, indicating the microporous nature of CMP samples (Fig. S8 and S9†). All adsorption isotherms featured a broad hysteresis loop where the desorption branch ran in parallel to the adsorption branch, joining it at the closure point at a low relative pressure of approximately 0.01. Desorption at such low relative pressures was so slow that equilibrium was only achieved after tens of hours. The phenomenon is apparently due to the elastic nature of the polymer network; the network expands during sorption because of the easy breakthrough of nitrogen molecules, whereas the driving force is substantially smaller during desorption, which results in retention or blocking of the adsorbate within the network. Due to the microporous nature of CMPs, the validity of the Brunauer-Emmett-Teller (BET) theory is questionable, being applicable only in a rather narrow range of relative pressures, typically from 0.05 to approximately 0.1-0.2. As BET surface areas are generally used for the characterization of CMPs, the BET surface areas are summarized together with the validity range and other textural parameters in Table 2.

In accordance with the idealized structure of 3D-DPP, this material contained the narrowest pores $(<1.8 \mathrm{~nm})$ of the series. When the porphyrin-porphyrin distance was enlarged by two phenyl units in 3D-TPP, the pore width grew to $2.1 \mathrm{~nm}$. 3D-DPP exhibited a larger pore volume than 3D-TPP, which might indicate some pore blocking by entrapped oligomers or interpenetration of the structure in 3D-TPP. 2D-TPP contained the widest micropores, approximately $2.0 \mathrm{~nm}$, which is in line with the material structure where the distance between the carbon atoms of the opposite phenyl rings was estimated to be approximately $2 \mathrm{~nm}$. The presence of $\mathrm{Pd}(\mathrm{II})$ in the structure of 2D-PdTPP led to the disappearance of any porosity and consequently to a considerable decrease in the BET surface area. In 3D-PdTPP, however, the porosity was retained, even though the pore width substantially decreased from 2.1 to $1.4 \mathrm{~nm}$ and the pore volume was reduced almost five times when compared with that of the 3D-TPP. The generally low porosity of 2D-PdTPP and 3D-PdTPP compared with that of metal-free counterparts can be related to the imposed planarity of the Pd(II) porphyrin units.

\section{Photophysical and photochemical properties}

The microporosity of CMP materials (Table 2) indicated good accessibility of the excited porphyrin units to oxygen, which is a fundamental prerequisite for the CMPs to act as efficient photosensitizers of $\mathrm{O}_{2}\left({ }^{1} \Delta_{\mathrm{g}}\right)$. In general, the processes after the excitation of porphyrin units involve the decay of the excited singlet states, ${ }^{1} \mathrm{P}^{*}$, via fluorescence (eqn (1)), non-radiative vibrational relaxation, and intersystem crossing leading to the low-lying triplet states, ${ }^{3} \mathrm{P}$ (eqn (2)). The triplet states are deactivated spontaneously via phosphorescence emission (eqn (3)), non-radiative relaxation, or by energy transfer with molecular oxygen in the ground state to form $\mathrm{O}_{2}\left({ }^{1} \Delta_{\mathrm{g}}\right)$ (eqn (4)). The spectral properties and kinetic parameters of the singlet and triplet states predetermine the formation of $\mathrm{O}_{2}\left({ }^{1} \Delta_{\mathrm{g}}\right)$; therefore, the absorption spectra and excited-state dynamics of the embedded porphyrin units were investigated in detail.

$$
\begin{gathered}
{ }^{1} \mathrm{P}^{*} \rightarrow{ }^{1} \mathrm{P}+h \nu_{\mathrm{F}} \\
{ }^{1} \mathrm{P}^{*} \rightarrow{ }^{3} \mathrm{P} \\
{ }^{3} \mathrm{P} \rightarrow{ }^{1} \mathrm{P}+h \nu_{\mathrm{p}} \\
{ }^{3} \mathrm{P}+\mathrm{O}_{2}\left({ }^{3} \Sigma_{\mathrm{g}}{ }^{-}\right) \rightarrow{ }^{1} \mathrm{P}+\mathrm{O}_{2}\left({ }^{1} \Delta_{\mathrm{g}}\right) \\
\mathrm{O}_{2}\left({ }^{1} \Delta_{\mathrm{g}}\right) \rightarrow \mathrm{O}_{2}\left({ }^{3} \Sigma_{\mathrm{g}}\right)+h \nu_{\mathrm{p}}
\end{gathered}
$$

The UV/Vis absorption spectra of CMP dispersions in acetonitrile displayed the characteristic Soret and Q bands of the porphyrin units (Fig. S10 and S11†). In comparison with the sharp Soret bands of monomeric porphyrins such as 5,10,15,20tetraphenylporphyrin at $413 \mathrm{~nm}$, embedding the porphyrin units into the polymer backbone led to a broadening and a shift to $440-450 \mathrm{~nm}$ with a shoulder at approximately $415 \mathrm{~nm}$. The Q bands were red-shifted, with a largest shift for 2D CMPs indicating the most extensive interaction between the porphyrin units in these materials. The spectral features are characteristics of porphyrin polymers. ${ }^{24}$ The $\mathrm{Q}(0,0)$ and $\mathrm{Q}(0,1)$ fluorescence bands were broadened and slightly shifted to 658-666 and 720$721 \mathrm{~nm}$, respectively, when compared with the corresponding bands at 647 and $714 \mathrm{~nm}$ measured for 5,10,15,20-

Table 2 Textural parameters and fluorescence lifetimes of the investigated CMPs in acetonitrile dispersions at room temperature ${ }^{a}$

\begin{tabular}{llllll}
\hline CMP & $S_{\text {BET }} / \mathrm{m}^{2} \mathrm{~g}^{-1}$ & $\left(P / P_{0}\right)_{\text {val }}$ & $V_{\text {pore }} / \mathrm{cm}^{3} \mathrm{~g}^{-1}$ & Pore width/nm & $\tau_{\mathrm{F}} / \mathrm{ns}$ \\
\hline 2D-TPP & 443 & $0.05-0.10$ & 0.18 & 2.0 & $0.5(82), 7.2(18)$ \\
2D-PdTPP & 37 & $0.05-0.20$ & - & Nonporous & - \\
3D-TPP & 353 & $0.05-0.25$ & 0.20 & 2.1 & $0.5(98), 4.1(2)$ \\
3D-PdTPP & 112 & $0.05-0.25$ & 0.043 & 1.4 & - \\
3D-DPP & 624 & $0.05-0.10$ & 0.29 & $<1.8$ & $\sim 0.2(92), 7.3(8)$
\end{tabular}

${ }^{a} S_{\mathrm{BET}}$ stands for the BET surface area calculated within the range of relative pressures $\left(P / P_{0}\right)_{\text {val }}$ ensuring the validity of the BET equation; $V_{\mathrm{pore}}$ is the pore volume determined by the BdB $t$-plot method; pore width was determined by the NLDFT method (Fig. S9); $\tau_{\mathrm{F}}$ are the fluorescence lifetimes (amplitude fractions in \% in parentheses). 


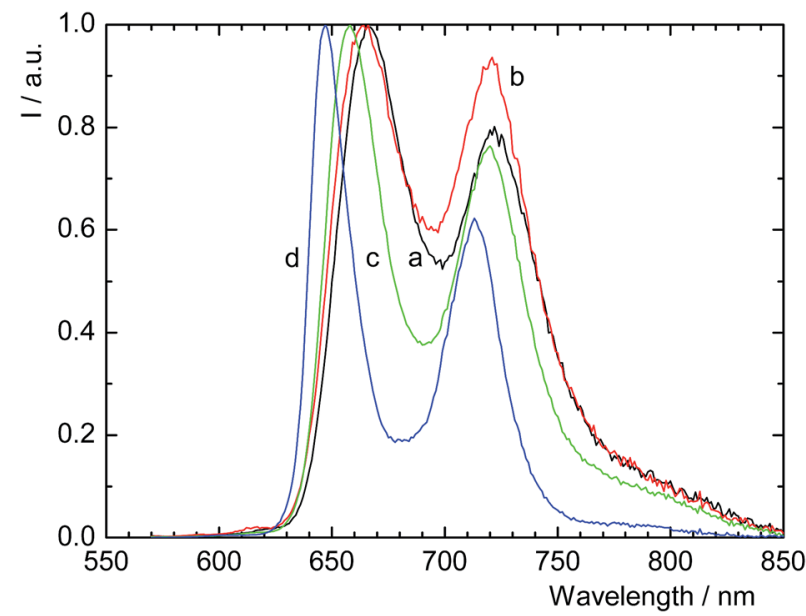

Fig. 2 Normalized fluorescence emission spectra of 2D-TPP (a), 3DDPP (b), and 3D-TPP (c) in acetonitrile dispersions $\left(\lambda_{\text {exc }}=520 \mathrm{~nm}\right.$ ) compared with that of 5,10,15,20-tetraphenylporphyrin in acetonitrile (d) $\left(\lambda_{\mathrm{exc}}=510 \mathrm{~nm}\right)$.

tetraphenylporphyrin in acetonitrile. In addition, the intensity of the $\mathrm{Q}(0,1)$ band increased at the expense of the $\mathrm{Q}(0,0)$ band (Fig. 2) and fluorescence lifetimes were considerably shortened (Table 2) as follows from comparison of the average fluorescence lifetimes of 1.7, 0.8, and $0.6 \mathrm{~ns}$ for 2D-TPP, 3D-DPP, and $3 \mathrm{D}$-TPP, respectively, with the single lifetime of $5,10,15,20$-tetraphenylporphyrin in acetonitrile being 9.2 ns. For completeness, the fluorescence excitation spectra of all measured samples matched the corresponding absorption spectra supporting the identity of the fluorescent components.

The dynamics of the triplet states directly predetermine the efficacy of $\mathrm{O}_{2}\left({ }^{1} \Delta_{\mathrm{g}}\right)$ photosensitization according to eqn (4). Because 2D-PdTPP and 3D-PdTPP contained phosphorescent Pd-porphyrin units, the dynamics of their triplet states were probed by luminescence spectroscopy. The emission spectra of 3D-PdTPP were considerably affected by oxygen (Fig. 3). While

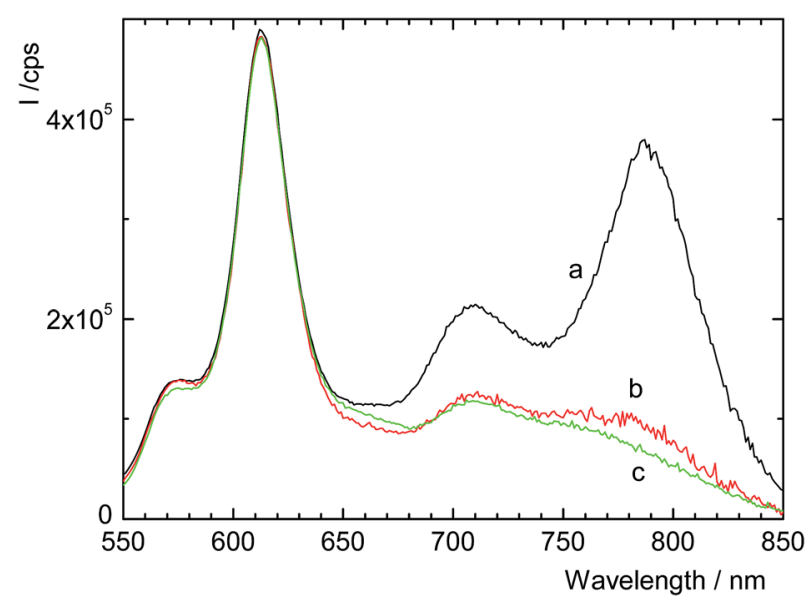

Fig. 3 Luminescence emission spectra of 3D-PdTPP dispersions in acetonitrile in the absence of oxygen (a), saturated by air (b) or oxygen (c). The excitation wavelength was $440 \mathrm{~nm}$. the fluorescence bands at 575 and $613 \mathrm{~nm}$ remained unchanged, the phosphorescence bands at 710 and approximately $785 \mathrm{~nm}$ were quenched considerably in the presence of oxygen. Phosphorescence decay curves recorded in the absence of oxygen were best analysed by a biexponential function giving an average lifetime of approximately $120 \mu \mathrm{s}$. This lifetime is in the same order of magnitude as the lifetimes of monomeric Pdporphyrins (e.g., $\mathrm{Pd}(\mathrm{II})-5,10,15,20$-tetrakis(4-sulfonatophenyl) porphyrin has a lifetime of $297 \mu \mathrm{s}$ in water). In contrast, the emission of 2D-PdTPP dispersions was only slightly affected by oxygen (Fig. S12 $\dagger$ ), which is in accordance with the nonporous character of this material with closely stacked porphyrin units leading to self-quenching of the excited states.

The above results document that the photophysical properties of the porphyrin units were affected by porphyrinporphyrin interactions within a polymeric backbone and/or between adjacent backbones. The formation of $\mathrm{O}_{2}\left({ }^{1} \Delta_{\mathrm{g}}\right)$ was indirectly indicated only for 3D-PdTPP on the basis of phosphorescence quenching by oxygen according to eqn (4) (Fig. 3). To prove the formation of $\mathrm{O}_{2}\left({ }^{1} \Delta_{\mathrm{g}}\right)$, we measured the $\mathrm{O}_{2}\left({ }^{1} \Delta_{\mathrm{g}}\right)$ luminescence emission of the solid samples in the near infrared region (eqn (5)). As anticipated, both palladium-containing 2D-PdTPP and 3D-PdTPP had a luminescence band at 1272 $\mathrm{nm}$, the characteristic of $\mathrm{O}_{2}\left({ }^{1} \Delta_{\mathrm{g}}\right)$ (Fig. S13 $\left.\dagger\right)$. The high intensity of the luminescence band of 3D-PdTPP suggested that this CMP is a better producer of $\mathrm{O}_{2}\left({ }^{1} \Delta_{\mathrm{g}}\right)$ than $2 \mathrm{D}$-PdTPP, in accordance with the phosphorescence results. The other CMPs exhibited only tiny signals of $\mathrm{O}_{2}\left({ }^{1} \Delta_{\mathrm{g}}\right)$ presence.

To document the photosensitizing properties of CMPs in more detail, we performed luminescence measurements in acetonitrile dispersions. The photoproduction of $\mathrm{O}_{2}\left({ }^{1} \Delta_{\mathrm{g}}\right)$ by 3D-PdTPP was proven by the appearance of the corresponding luminescence band and by a strong dependence of the peak intensity on oxygen concentrations (Fig. 4). Clearly, no $\mathrm{O}_{2}\left({ }^{1} \Delta_{\mathrm{g}}\right)$ was produced in the absence of oxygen. Similar behaviour was observed for 2D-PdTPP and 3D-TPP dispersions (Fig. S14 and $\mathrm{S} 15 \dagger)$; however, the intensities of photosensitized $\mathrm{O}_{2}\left({ }^{1} \Delta_{\mathrm{g}}\right)$ were

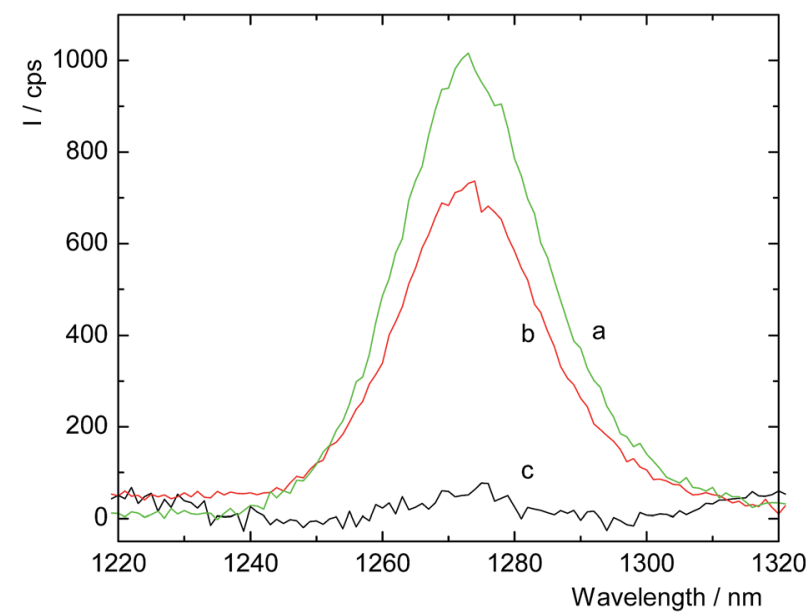

Fig. 4 Luminescence emission spectra of photosensitized $\mathrm{O}_{2}\left({ }^{1} \Delta_{\mathrm{g}}\right)$ produced in acetonitrile dispersions of 3D-PdTPP in oxygen (a), air (b), and argon atmosphere (c) upon excitation at $420 \mathrm{~nm}$. 
much smaller when compared with the activity of 3D-PdTPP. In contrast, 3D-DPP (Fig. S16 $\dagger$ ) and 2D-TPP (Fig. 5) dispersions produced $\mathrm{O}_{2}\left({ }^{1} \Delta_{\mathrm{g}}\right)$ even after long-term purging of the dispersions with argon. These results indicate that molecular oxygen is quite difficult to remove from the microporous structure of both CMPs, such that these polymeric networks retain oxygen even in an argon atmosphere. As mentioned, the 3D-DPP network has large pore volumes with quite narrow pores $(<1.8$ $\mathrm{nm}$ ) (Table 2). The pore width of 2D-TPP is $2.0 \mathrm{~nm}$.

CMPs, composed of building blocks with a photosensitization functionality, can be good candidates for novel $\mathrm{O}_{2}\left({ }^{1} \Delta_{\mathrm{g}}\right)$ photosensitizers. The porphyrin units themselves used in this work are good $\mathrm{O}_{2}\left({ }^{1} \Delta_{\mathrm{g}}\right)$ sensitizers. However, when the porphyrin units become a part of the porous polymer network, it is difficult to accurately access the effectivity of the formation of the porphyrin triplet states (eqn (2)), and, consequently, the effectivity of $\mathrm{O}_{2}\left({ }^{1} \Delta_{\mathrm{g}}\right)$ generation (eqn (4)). This is because the porphyrin units tend to undergo $\pi-\pi$ stacking interactions that lead to fast competitive non-radiative relaxations of the excited states that diminish $\mathrm{O}_{2}\left({ }^{1} \Delta_{\mathrm{g}}\right)$ productivity. For comparison, benzothiadiazole $-^{44}$ and zinc phthalocyanine-based ${ }^{45}$ CMPs were identified as solid-state photosensitizers of $\mathrm{O}_{2}\left({ }^{1} \Delta_{\mathrm{g}}\right)$ under irradiation by visible and $700 \mathrm{~nm}$ light on the bases of indirect experiments. Similarly, the selective oxidation of thioanisole into the corresponding sulfoxide under visible light irradiation, occurring in the presence of BODIPY-based CMP, was attributed to a $\mathrm{O}_{2}\left({ }^{1} \Delta_{\mathrm{g}}\right)$ reaction channel. ${ }^{46}$ In contrast to these works, the presented results here prove directly the formation of triplet states and $\mathrm{O}_{2}\left({ }^{1} \Delta_{\mathrm{g}}\right)$, and therefore unambiguously indicate that the porphyrin-based CMPs can be considered as promising $\mathrm{O}_{2}\left({ }^{1} \Delta_{\mathrm{g}}\right)$ photosensitizers.

\section{Photosensitization activity}

Driven by the motivation to utilize the porphyrin-based CMPs as solid-state photosensitizers of $\mathrm{O}_{2}\left({ }^{1} \Delta_{\mathrm{g}}\right)$, we investigated the $\mathrm{O}_{2}\left({ }^{1} \Delta_{\mathrm{g}}\right)$ production efficiency in a reaction of 9,10-diphenylanthracene to its corresponding endoperoxide (Scheme 2). The

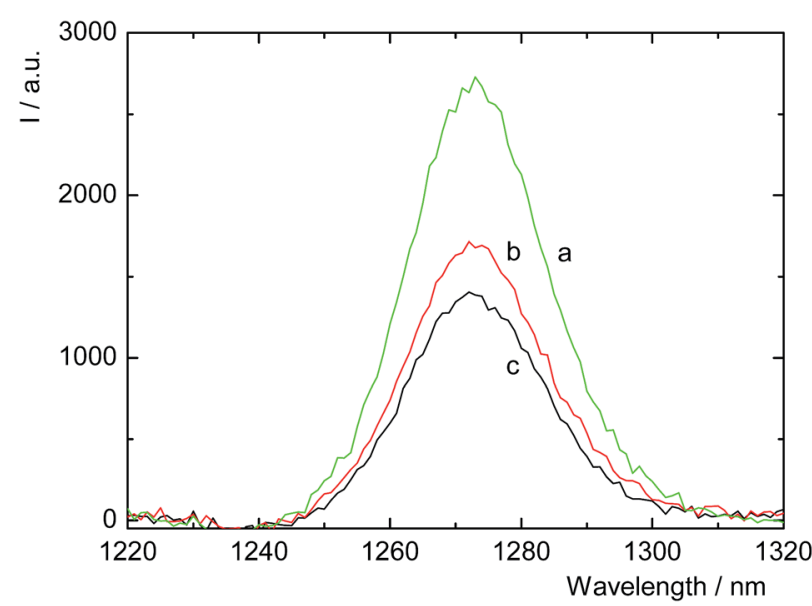

Fig. 5 Luminescence emission spectra of photosensitized $\mathrm{O}_{2}\left({ }^{1} \Delta_{\mathrm{g}}\right)$ produced in acetonitrile dispersions of 2D-TPP in oxygen (a), air (b), and argon atmosphere (c) upon excitation at $420 \mathrm{~nm}$.<smiles>c1ccc(-c2c3ccccc3c(-c3ccccc3)c3ccccc23)cc1</smiles><smiles></smiles>

Scheme 2 Reaction of $\mathrm{O}_{2}\left({ }^{1} \Delta_{\mathrm{g}}\right)$ with 9,10-diphenylanthracene.

reaction kinetics were followed by a concentration decrease of 9,10-diphenylanthracene recorded using UV/Vis spectroscopy. Blank experiments excluded the substrate sorption by the CMPs and the substrate reaction upon irradiation in the absence of the CMPs. As presented in Fig. 6, the kinetics strongly depend on the porphyrin arrangement in the CMPs. Two samples, 3D-PdTPP and 3D-TPP, exhibited the most effective photosensitizing activity, whereas 2D-PdTPP and 3D-DPP were the least photosensitizing materials. Based on these results, it is evident that the activity of the CMPs to produce $\mathrm{O}_{2}\left({ }^{1} \Delta_{\mathrm{g}}\right)$ available to react with the substrate can be correlated with neither the BET surface area nor with the corresponding pore volume, as these characteristics are quite low in the most effective 3D-PdTPP compared with the other CMPs (Table 2). In general, $\mathrm{O}_{2}\left({ }^{1} \Delta_{\mathrm{g}}\right)$ produced by a CMP particle can be formed at the external surface and/or in the bulk including the pores, and therefore the reactions of $\mathrm{O}_{2}\left({ }^{1} \Delta_{\mathrm{g}}\right)$ with a target species, commonly located at the surface, in pores, or in the close surroundings of a particle, depend on the ability of $\mathrm{O}_{2}\left({ }^{1} \Delta_{\mathrm{g}}\right)$ to reach these locations. This originates from the fact that $\mathrm{O}_{2}\left({ }^{1} \Delta_{\mathrm{g}}\right)$ has a relatively short lifetime, limiting its oxidation power to the proximity of a site where it was formed. This reasoning suggests that materials with good accessibility of the porphyrin units to

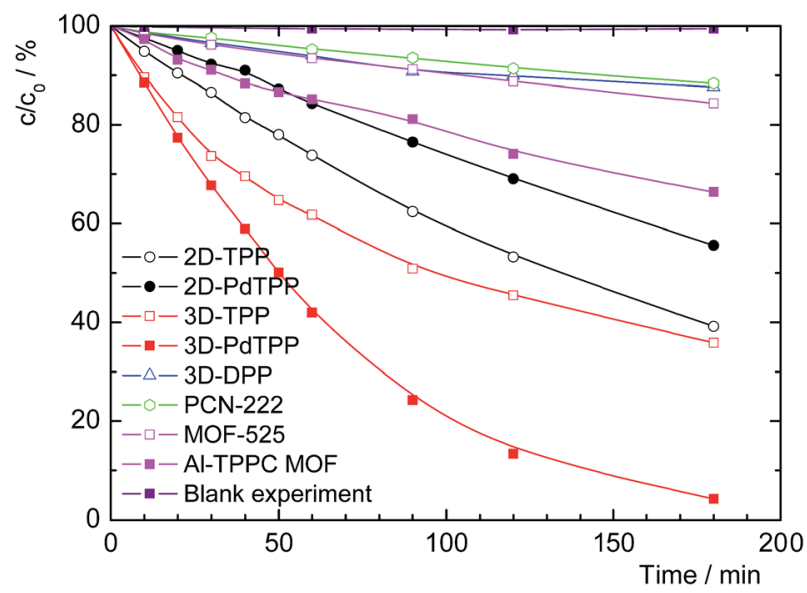

Fig. 6 Reaction of photosensitized $\mathrm{O}_{2}\left({ }^{1} \Delta_{g}\right)$ produced by CMP and MOF dispersions in acetonitrile with 9,10-diphenylanthracene according to Scheme 2. 
oxygen and a low degree of porphyrin-porphyrin interactions have high photosensitizing activities, which is probably the case with 3D-PdTPP and 3D-TPP. On the other hand, the very low activity, especially of 3D-DPP, can be due to a close arrangement of the porphyrin units resulting in the quenching of the porphyrin triplet states.

To broaden the examination of porphyrin polymers, we also investigated the photosensitizing activity of porphyrin containing water-stable MOFs; namely, we synthesized PCN-222, ${ }^{47}$ MOF-525, ${ }^{48}$ and Al-TPPC MOF. ${ }^{49}$ The amount of MOFs in the experiments was adjusted to the same content of porphyrin units as used in the CMPs. Even though the porphyrin units in the MOFs do not stack together and the MOFs display significantly higher porosity than the CMPs (BET surface area: 2300, 2600, and $1400 \mathrm{~m}^{2} \mathrm{~g}^{-1}$ for PCN-222, MOF-525, and Al-TPPC MOF, respectively), the endoperoxide formation was rather low when compared with the activity of the CMPs. Having established the photosensitizing activities of a series of porphyrin-based materials, it is clear that structural and chemical composition differences of the immediate porphyrin environment cause significant variations in the $\mathrm{O}_{2}\left({ }^{1} \Delta_{\mathrm{g}}\right)$ production.

To prove the stability and repeatable applicability of CMP photosensitizers, the most active 3D-PdTPP was separated after the complete reaction and reused in a new run. As presented in Fig. S17, $\dagger$ the photosensitizer preserved its activity and can be repeatedly used. To analyse the effects of oxygen concentration, some irradiation experiments were performed in an argon atmosphere. Both 2D-PdTPP and 2D-TPP decreased the 9,10diphenylanthracene concentration down to $54.7 \pm 0.9$ and 40.3 $\pm 1.1 \%$, respectively, after 3 hours of irradiation in air. In agreement with the excitation scheme (eqn (1)-(4)), the photosensitizing activity of 2D-PdTPP completely diminished in the absence of oxygen. In contrast, the usage of 2D-TPP in an argonsaturated dispersion decreased the substrate concentration down to $88.5 \%$. This finding is in agreement with the behaviour of 2D-TPP described above (Fig. 5) and confirms that oxygen in 2D-TPP is confined in the microporous structure of the polymer network and cannot be easily removed as in the case of $2 \mathrm{D}$ PdTPP. This can be advantageous in systems where the concentration of oxygen is fluctuating with a constant need for $\mathrm{O}_{2}\left({ }^{1} \Delta_{\mathrm{g}}\right)$ generation.

\section{Conclusions}

The presented materials are a platform for the fabrication of heterogeneous photosensitizers functioning under visible light. They are photostable, and their nature allows for simple separation and reusing. We prepared a series of new porphyrincontaining 3D CMPs with a diamond-like topology and compared their photophysical properties with those of corresponding 2D CMPs and water-stable MOFs. It is evident that the activity of CMPs in the $\mathrm{O}_{2}\left({ }^{1} \Delta_{\mathrm{g}}\right)$-based reactions cannot be directly correlated with their BET surface area nor with their pore volume, but strongly correlates with the immediate porphyrin environment. When porphyrins are horizontally stacked, as in the 2D CMPs, or are separated by a short organic linker (3D-DPP), most of the absorbed light energy is dissipated by non-radiative processes. Enlarging the porphyrin separation, as in 3D-PdTPP and 3D-TPP, leads to effective solid photosensitizers that display a significantly higher activity. Compared with the MOFs, the CMPs offer greater control over the porphyrin environment and superior stability by replacing susceptible coordination bonds with robust covalent bonds; therefore, the CMPs are more suitable and more efficient photosensitizers.

The CMP materials represent a substantial step forward in the fabrication of heterogeneous photosensitizers acting under visible light. They are photo- and chemically stable, and their nature allows for recycling and utilization in composites for the construction of antimicrobial coatings under visible light. Ongoing research is focused on the development of composites by fixing porous CMP nanoparticles on polymeric surfaces and dispersing them as fillers into continuous polymeric matrices.

\section{Acknowledgements}

This work was supported by the Czech Science Foundation (No. 16-15020S). J. H. gratefully acknowledges the Grant Agency of the Charles University in Prague (No. 252216) for financial support.

\section{Notes and references}

1 J. Mosinger, K. Lang and P. Kubát, Top. Curr. Chem., 2016, 370, 135-168.

2 M. Wainwright, J. Antimicrob. Chemother., 1998, 42, 13-28.

3 C. Spagnul, L. C. Turner and R. W. Boyle, J. Photochem. Photobiol., B, 2015, 150, 11-30.

4 E. Alves, M. A. F. Faustino, M. G. P. M. S. Neves, Â. Cunha, H. Nadais and A. Almeida, J. Photochem. Photobiol., C, 2014, 22, 34-57.

5 X. Feng, X. Ding and D. Jiang, Chem. Soc. Rev., 2012, 41, 6010-6022.

6 N. U. Day, C. C. Wamser and M. G. Walter, Polym. Int., 2015, 64, 633-657.

7 A. P. Côté, A. I. Benin, N. W. Ockwig, M. O'Keeffe, A. J. Matzger and O. M. Yaghi, Science, 2005, 310, 1166-1170.

8 J.-X. Jiang, F. Su, A. Trewin, C. D. Wood, N. L. Campbell, H. Niu, C. Dickinson, A. Y. Ganin, M. J. Rosseinsky, Y. Z. Khimyak and A. I. Cooper, Angew. Chem., Int. Ed., 2007, 46, 8574-8578.

9 S. D. Brucks, D. N. Bunck and W. R. Dichtel, Polymer, 2014, 55, 330-334.

10 J. Zhang, L. Wang, N. Li, J. Liu, W. Zhang, Z. Zhang, N. Zhou and X. Zhu, CrystEngComm, 2014, 16, 6547-6551.

11 X. Liu, H. Li, Y. Zhang, B. Xu, A. Sigen, H. Xia and Y. Mu, Polym. Chem., 2013, 4, 2445-2448.

12 V. S. P. K. Neti, X. Wu, S. Deng and L. Echegoyen, Polym. Chem., 2013, 4, 4566-4569.

13 R. K. Totten, Y.-S. Kim, M. H. Weston, O. K. Farha, J. T. Hupp and S. T. Nguyen, J. Am. Chem. Soc., 2013, 135, 11720-11723.

14 G. Lu, H. Yang, Y. Zhu, T. Huggins, Z. J. Ren, Z. Liu and W. Zhang, J. Mater. Chem. A, 2015, 3, 4954-4959. 
15 L. Chen, Y. Honsho, S. Seki and D. Jiang, J. Am. Chem. Soc., 2010, 132, 6742-6748.

16 A. I. Cooper, Adv. Mater., 2009, 21, 1291-1295.

17 X. Feng, L. Chen, Y. Dong and D. Jiang, Chem. Commun., 2011, 47, 1979-1981.

18 F. J. Uribe-Romo, J. R. Hunt, H. Furukawa, C. Klöck, M. O'Keeffe and O. M. Yaghi, J. Am. Chem. Soc., 2009, 131, 4570-4571.

19 X.-J. Zhang, N. Bian, L.-J. Mao, Q. Chen, L. Fang, A.-D. Qi and B.-H. Han, Macromol. Chem. Phys., 2012, 213, 1575-1581.

20 L. Zou, D. Feng, T.-F. Liu, Y.-P. Chen, S. Fordham, S. Yuan, J. Tian and H.-C. Zhou, Chem. Commun., 2015, 51, 40054008.

21 Q. Fang, S. Gu, J. Zheng, Z. Zhuang, S. Qiu and Y. Yan, Angew. Chem., Int. Ed., 2014, 53, 2878-2882.

22 X.-D. Li, J.-H. Guo, H. Zhang, X.-L. Cheng and X.-Y. Liu, RSC Adv., 2014, 4, 24526-24532.

23 Z. Wang, S. Yuan, A. Mason, B. Reprogle, D.-J. Liu and L. Yu, Macromolecules, 2012, 45, 7413-7419.

24 X. Liu, Y. Xu, Z. Guo, A. Nagai and D. Jiang, Chem. Commun., 2013, 43, 3233-3235.

25 S. Wan, F. Gándara, A. Asano, H. Furukawa, A. Saeki, S. K. Dey, L. Liao, M. W. Ambrogio, Y. Y. Botros, X. Duan, S. Seki, J. K. Stoddart and O. M. Yaghi, Chem. Mater., 2011, 23, 4094-4097.

26 Z.-S. Wu, L. Chen, J. Liu, K. Parvez, H. Liang, J. Shu, H. Sachdev, R. Graf, X. Feng and K. Müllen, Adv. Mater., 2014, 26, 1450-1455.

27 L. Chen, Y. Yang and D. Jiang, J. Am. Chem. Soc., 2010, 132, 9138-9143.

28 A. M. Shultz, O. K. Farha, J. T. Hupp and S. T. Nguyen, Chem. Sci., 2011, 2, 686-689.

29 S. Jesenská, L. Plíštil, P. Kubát, K. Lang, L. Brožová, S. Popelka, L. Szatmáry and J. Mosinger, J. Biomed. Mater. Res., Part A, 2011, 99, 676-683.

30 E. Káfuňková, K. Lang, P. Kubát, M. Klementová, J. Mosinger, M. Šlouf, A.-L. Troutier-Thuilliez, F. Leroux, V. Verney and C. Taviot-Guého, J. Mater. Chem., 2010, 20, 9423-9432.
31 M. Merchán, T. Sothea Ouk, P. Kubát, K. Lang, C. Coelho, V. Verney, S. Commereuc, F. Leroux, V. Sol and C. TaviotGuého, J. Mater. Chem. B, 2013, 1, 2139-2146.

32 K. Lang, J. Mosinger and D. M. Wagnerová, Coord. Chem. Rev., 2004, 248, 321-350.

33 J. Demel and K. Lang, Eur. J. Inorg. Chem., 2012, 2012, 51545164.

34 J. Demel, P. Kubát, I. Jirka, P. Kovář, M. Pospíšil and K. Lang, J. Phys. Chem. C, 2010, 114, 16321-16328.

35 E. Káfuňková, C. Taviot-Guého, P. Bezdička, M. Klementová, P. Kovár, P. Kubát, J. Mosinger, M. Pospíšil and K. Lang, Chem. Mater., 2010, 22, 2481-2490.

36 J. Demel, P. Kubát, F. Millange, J. Marrot, I. Císařová and K. Lang, Inorg. Chem., 2013, 52, 2779-2786.

37 J. Park, D. Feng, S. Yuan and H.-C. Zhou, Angew. Chem., Int. Ed., 2015, 54, 430-435.

38 L. Zhang, J. Lei, F. Ma, P. Ling, J. Liu and H. Ju, Chem. Commun., 2015, 51, 10831-10834.

39 M. C. C. Ng, J. B. Harper, A. P. J. Stampfl, G. J. Kearley, S. Rols and J. A. Stride, Chem.-Eur. J., 2012, 18, 13018-13024.

40 J.-H. Fournier, T. Maris, J. D. Wuest, W. Guo and E. Galoppini, J. Am. Chem. Soc., 2003, 125, 1002-1006.

41 T. Rohand, E. Dolusic, T. N. Ngo, W. Maes and W. Dehaen, ARKIVOC, 2007, 307-324.

42 L. Yu and J. S. Lindsey, Tetrahedron, 2001, 57, 9285-9298.

43 M. Zawadzka, J. Wang, W. J. Blau and M. O. Senge, J. Phys. Chem. A, 2013, 117, 15-26.

44 B. C. Ma, S. Ghasimi, K. Landfester, F. Vilela and K. A. I. Zhang, J. Mater. Chem. A, 2015, 3, 16064-16071.

45 X. Ding and B.-H. Han, Angew. Chem., Int. Ed., 2015, 54, 6536-6539.

46 M. Liras, M. Iglesias and F. Sánchez, Macromolecules, 2016, 49, 1666-1673.

47 D. Feng, Z.-Y. Gu, J.-R. Li, H.-L. Jiang, Z. Wei and H.-C. Zhou, Angew. Chem., Int. Ed., 2012, 51, 10307-10310.

48 W. Morris, B. Volosskiy, S. Demir, F. Gándara, P. L. McGrier, H. Furukawa, D. Cascio, J. F. Stoddart and O. M. Yaghi, Inorg. Chem., 2012, 51, 6443-6445.

49 A. Fateeva, P. A. Chater, C. P. Ireland, A. A. Tahir, Y. Z. Khimyak, P. V. Wiper, J. R. Darwent and M. J. Rosseinsky, Angew. Chem., Int. Ed., 2012, 51, 7440-7444. 